Copyright by the MIT Press. Burian, Richard M. "The Dilemma of Case Studies Resolved: The Virtues of Using Case Studies in the History and Philosophy of Science," Perspectives on Science, Winter 2001, Vol. 9, No. 4, Pages 383-404. doi:10.1162/106361401760375794

\title{
The Dilemma of Case Studies Resolved: The Virtues of Using Case Studies in the History and Philosophy of Science
}

\author{
Richard M. Burian \\ Department of Philosophy and Center \\ for Science and Technology Studies \\ Virginia Polytechnic Institute and \\ State University Blacksburg, Virginia \\ 24061-0126
}

Philosophers of science turned to historical case studies in part in response to Thomas Kubn's insistence that such studies can transform the philosophy of science. In this issue Joseph Pitt argues that the power of case studies to instruct us about scientific methodology and epistemology depends on prior philosophical commitments, without which case studies are not philosophically useful. Here I reply to Pitt, demonstrating that case studies, properly deployed, illustrate styles of scientific work and modes of argumentation that are not well handled by currently standard philosophical analyses. I illustrate these claims with exemplary findings from case studies dealing with exploratory experimentation and with interdisciplinary cooperation across sciences to yield multiple independent means of access to theoretical entities. The latter cases provide examples of ways that scientists support claims about theoretical entities that are not available in work performed within a single discipline. They also illustrate means of correcting systematic biases that stem from the commitments of each discipline taken separately. These findings illustrate the transformative power of case study methods, allow us to escape from the horns of Pitt's "dilemma of case studies," and vindicate some of the post-Kubn uses to which case studies have been put.

Earlier versions of this paper were delivered in four venues: at a meeting on "Science and Culture" at Lake Como in September 1999, during a senior fellowship at the Center for History of Recent Science, George Washington University, at the Institute for Advanced Studies on Science Technology and Society, Graz, Austria and at the Virginia Tech Kuhn Retrospective Symposium. The present version has benefited from discussions at each of these occasions. I am grateful to all of the discussants and especially to Joseph Pitt for the stimulus to develop my views on this topic. A shorter paper with considerable overlap is in press in the Yearbook 2002 of the Institute for Advanced Studies on Science Technology and Society as "The Dilemma of Case Studies Resolved: On the Usefulness of Historical Case Studies in the Philosophy of Science."

Perspectives on Science 2001, vol. 9, no. 4

(C) 2002 by The Massachusetts Institute of Technology 


\section{Introduction}

As Joseph Pitt argues in this issue, the heavy use of case studies in the philosophy of science in the last few decades has been, among other things, a response to Thomas Kuhn's influential argument that "history, if viewed as a repository for more than anecdote or chronology, could produce a decisive transformation in the image of science by which we are now possessed" (Kuhn 1962, p. 1). Pitt argues forcefully that case studies are not able to perform the functions that Kuhn set forth for them and that, implicitly and explicitly, philosophers of science expected them to fulfill. In this paper, I argue that Pitt's dilemma for case study work is ill founded so that the dilemma does not undermine the uses to which Kuhn expected them to be put, but that some of his claims about how best to make case studies philosophically useful are nonetheless correct. My argument relies on the fact that scientific change is considerably more orderly than Pitt's Heracleiteanism suggests. At any time, within particular domains (or problematics), some claims are relatively better established than others and some techniques more reliable than others. Furthermore, to overturn the relative epistemic position of such claims and techniques, rather specific burdens are placed on their critics. In effect, there is a rough and ready epistemic consensus about the relative vulnerability of certain key claims in particular scientific communities, at least within certain domains (see Burian 1985; Burian 2003 [in press]). This is part of what gave Kuhn's muddy notion of a paradigm its initial plausibility. In favorable cases, the existence of this sort of local_or, perhaps, regional_consensus, enables case studies to achieve reasonable agreement about the boundaries of a case study, the relevance of some putative contextual factors, and so on. Accordingly, I am considerably more optimistic than Prof. Pitt about what we gain from well-executed case studies. I will argue that, properly deployed, they can yield deeper understanding of science than alternative methods and that they ought to play a greater role in philosophy of science than the mainly heuristic one to which he relegates them.

\section{What are Case Studies?}

Prof. Pitt's account of case studies in the history of science is narrower than mine, so it is worth stopping for a moment to ask what we each mean. Case studies are concerned with scientific work carried out during a limited time period and are usually restricted to a specified set of scientists, institutions, laboratories, disciplines, or traditions. They may, but need not, be focused on an individual scientist. They typically focus on work in a specified domain or on some specified topic (what Pitt calls a "problematic")_for example, on work on black body radiation, or locating black 
holes, or the material composition of genes, etc. The issues examined may be quite heterogeneous. For example, there are case studies concerned with the research strategies of particular individuals or laboratories, differences between particular research programs, the impact of a new technology on a particular research problem, what went into transforming an instrument devised for one purpose to suit it to a different job, and on the impact of funding from a particular patron or foundation on the content of particular scientific work. Occasionally, the topics are quite large. Thus, a number of people have done interlocking case studies in order to compare treatments of the problem of heredity in different biological disciplines around the turn of the twentieth century. But case studies usually deal with relatively narrow topics. And most of the case studies that interest philosophers of science are organized around a focal issue of broad interest, for example the relationship between theoretical and technological innovation in certain lines of scientific work or the strengths and weaknesses of particular research methods or technologies in a certain domain.

I will defend uses of case studies that begin with some general knowledge of the focal issue toward which the case study(ies) are directed, but do not deploy the cases in hypothetico-deductive style as a test of (universal) philosophical theses about the place of values in science, or about scientific method, epistemology, or metaphysics. ${ }^{1}$ There is a deep reason for this. Like Prof. Pitt and many others I do not believe that there is such a thing as the place of values in science, the scientific method, or the epistemology or metaphysics of science. This theme will recur throughout the paper, and my treatment will yield an argument that it does not have the Heracleitean consequences that Pitt thinks it does.

\section{A Review of the Dilemma}

Pitt's dilemma may be summarized as follows. On the one hand, if we choose our cases to support, illustrate, or even test a general philosophical or methodological claim about science, our sampling procedure and interpretation of the case will be, indeed, must be, systematically biased. The philosopher's interpretation of the material covered in the case study must be shaped by the very methodological or epistemological claim that is to be tested. Accordingly, this procedure reinterprets the historical record, usually anachronistically, in terms of the very methodological thesis that is at stake. It also ignores all parts of science to which the thesis being considered is not germane. This is not just Pitt's position; similar claims are put forward by Joseph Agassi, Paul Feyerabend, Thomas Kuhn, Imre 
Lakatos, and Larry Laudan, among others. Because the cases are chosen and manipulated in these ways, this procedure is guilty (perhaps inadvertently) of systematically cooking data to fit the investigation at hand. As is familiar, Imre Lakatos (Lakatos 1971, 1972) suggests a rather impractical way to escape this horn of the dilemma. Expose each philosophical methodology to all the cases considered by all of the competing philosophical methodologies. Exclude the trivially mistaken methodology that considers all science to be rational. The best methodology examined is the one that evaluates the greatest number of these cases as behaving in accordance with sound methodology, for it maximizes the rationality of science. Unfortunately, however, this test assumes that the methodology that maximizes the number of cases that are considered rational has assigned credit and demerits correctly. There is no independent standpoint available to certify the correctness of this assumption or to vouchsafe the particular assignments of rationality (or lack thereof) by this procedure. There are a number of variants on this strategy, e.g., Larry Laudan's use of touchstone judgments by scientists (Laudan 1977), but they are all subject to similar objections.

Alternatively, if we start a case study without any philosophical issue in mind, it is unclear what sort of moral we can or should draw. The risk of hasty generalization is enormous. A series of case studies - even a few hundred of them for that matter-does not provide a sufficient basis for generalizing about science, which is as richly diverse as any human enterprise. Unless the sample is appropriate and is not skewed by systematic bias this problem is insurmountable - and to know that the sample is appropriate and unbiased, one would already have to know how to determine whether a case should count as an instance of good science. Thus, philosophers and historians who start from case studies cannot prevent systematic bias or hasty generalization. Conclusion: without independent support, methodological or philosophical morals drawn from case studies are untrustworthy. ${ }^{2}$

This argument is often used to support a philosophical stance that Kuhn opposed (as do the contributors to this issue). I call it top-down philosophy of science because its adherents maintain that we should be able to support or derive norms for science or standards of scientific knowledge from strictly philosophical considerations (usually epistemological, sometimes metaphysical). Thus we work 'down' from philosophy to an account

2. See Prof. Pitt's contribution to this issue. Ironically, as I will argue, Pitt does not accept the flawed assumptions about science that are required to make this argument plausible and argues in favor of many of the uses of case studies that I advocate in this paper. 
of the nature or aims of science and/or the methods appropriate to science. Much of the work of Rudolf Carnap and Karl Popper at mid-century fits this description and, in spite of themselves, we find echoes of it in the work of such historically oriented philosophers of science as Imre Lakatos and Larry Laudan, both of them influenced by Popper. Among our contemporaries, I suggest that such Bayesian philosophers as Colin Howson and Peter Urbach (Howson and Urbach 1989) and Allan Franklin (Franklin 1990) practice top-down philosophy. Although top-down work is not now fashionable in science studies and is widely contested in philosophy of science, it is still enormously influential, not only among philosophers, but also among scientists and in the popular image of science. Top-down thinking infects anyone who thinks that there is such a thing as the method of science or that science has an essence. Thus, for example, those who think that science, done properly, is necessarily self-correcting or is based simply on a search for the truth or on describing phenomena economically is ascribing an essence to science and will approach cases in a top-down manner.

\section{A Response to the Dilemma}

Prof. Pitt's dilemma is a false dilemma. It should be persuasive only if one accepts flawed assumptions about science or misunderstands the proper application of case study methods. Science is not one thing. It cannot be properly characterized by abstract principles or by snapshots (i.e., by temporally isolated case studies); rather, to understand what happens in a particular scientific episode, one must pay close attention to historical context, particularly the special social contexts within which science is done. Accordingly, case studies should be grouped in such a way as to take account of the context in which the work was done and of relevant shifts in context. So far, Pitt and I agree, except, perhaps for a trivial semantic difference, for he doesn't seem to think that what I call grouped case studies are case studies.

I will explore two ways of grouping case studies, both quite powerful. The first is to construct longitudinal studies of work bearing on a particular scientific problem, that is, studies that follow the evolution of the problem and of scientists' ways of dealing with it. The second is to set up comparative studies of approaches to a problem taken by workers in different laboratories or disciplines or by use of different tools and technologies. To be effective, such studies need to take account of the multiple settings within which scientific work takes place-theoretical, technical, instrumental, institutional, political, financial, national ... Context here is like a set of matroshkis, i.e., nested Russian dolls, except that the nesting can 
be continued indefinitely and in several directions. Nonetheless, and Pitt and I apparently disagree about this, for practical purposes the contexts to be considered can usually be limited by requiring clear demonstration of their relevance to the execution of the scientific work or the historical resolution of the issues at stake.

Thus, I maintain, the best use of case studies is "bottom-up." The point of case study methods is to work up from an appreciation of the scientific work in its context. A case study does its job only if it yields improved understanding of how scientists solved (or failed to solve) problems, what methods they used or tried to use, how their various tools were made to interact, how they evaluated hypotheses and factual claims, and so on. If one is willing to count work as genuinely scientific only if it meets a pre-set criterion or general aim (such as truth seeking), then one is not honestly working bottom up and risks misunderstanding the case. This does not mean that one proceeds in a philosophical vacuum. Cases are chosen in part for philosophical reasons. We will see how this works shortly.

In an attempt at reflexive self-consistency, I will argue against the philosophers' dilemma by working the way I claim is desirable-bottom up, from case studies. Given space limitations, I will have to be extremely telegraphic, adumbrating rather than constructing case studies. For convenience, I will draw on some of my own case study work, which has been both longitudinal and comparative, and has dealt with cases in developmental and evolutionary biology and in genetics. In drawing on these case studies, the philosophical issues I have in the back of my mind are these:

1. How do biologists deal with complex situations for which they do not have adequate theories? More specifically, what can we learn from appropriate case studies about ways in which biologists have balanced between high theory and powerful techniques?

2. What light can case study work shed on epistemological aspects of the interactions among scientists trained in different disciplines?

My answers to these two questions yield a response to the dilemma. Case studies can produce findings that cannot be gotten from more abstract 'armchair' philosophical work; methodologically and epistemologically useful case studies need not be philosophically innocent and need not proceed to grand conclusions by induction from absurdly small samples.

Topic One: Following Complex Interactions in the Absence of High Theory To sketch an account of some ways of proceeding in the face of very limited theoretical knowledge I will draw on a case study that deals with investigations that began with very little guidance from theory and in near 
total ignorance of the answers to the questions at hand. It is noteworthy that in this and many other cases, the development of, and reliance on, powerful new exploratory technologies and techniques is crucial. ${ }^{3}$

Case 1: Localization and Distribution of Nucleic Acids. ${ }^{4}$ Jean Brachet (1909-1988), son of the Belgian embryologist and cytologist Albert Brachet, began to work on the localization and distribution of nucleic acids in 1927. His first major article on this topic, on which he worked more-or-less continuously well into the 1970s, was published in 1929. Brachet was very much a hands-on experimental scientist, always devising and exploiting new techniques. His 1957 book, Biochemical Cytology (Brachet 1957), was the bible of methods in that field for a number of years.

Brachet began to work on the nucleic acids long before DNA was suspected to be the genetic material. His initial interest centered on biochemical embryology, and most of his early investigations were directed to finding out the distributions and roles of the nucleic acids in the development of a great variety of embryos. One phase of this work, from roughly 1940 to 1952 is of particular interest here, among other things because it led him smack into the problem of understanding protein synthesis. Crystallized RNAse, an enzyme that attacks RNA but not DNA, became available in 1938. By 1940 Brachet had worked out a technique using this enzyme that enabled him to stain RNA and DNA differentially in successive microtome slices of cells and tissues. With this technique he was able to make pretty good quantitative estimates of the distribution of DNA and RNA within embryos and cells. Many organisms had about as much total RNA in the cytoplasm of their newly fertilized eggs as they had DNA in the nuclei of their cells by the time they formed a gastrula, i.e., when they had hundreds or thousands of cells. During this period of the embryo's life, the amount of RNA went down in proportion to the increase of DNA. Thus Brachet's first hypothesis, quite reasonable given the available evidence, was that RNA is a precursor of DNA, required for synthesis of DNA.

From 1940 to 1952 he gradually refined his techniques. (He even cooked up radioactive compounds in a backyard oven when he wasn't allowed into his laboratory during the Second World War.) By 1952 he had

3. In passing, I note that there is special benefit here in working on recent science. Thanks to many developments in the twentieth century, one can study the impact of the enormous battery of powerful tools available for use in exploratory experimentation when high theory is not available.

4. See (Sapp 1986; Burian 1994, 1996; Thieffry and Burian 1996; Burian 1997b; Burian and Thieffry 1997; Rheinberger 1997a; Sapp 1997). 


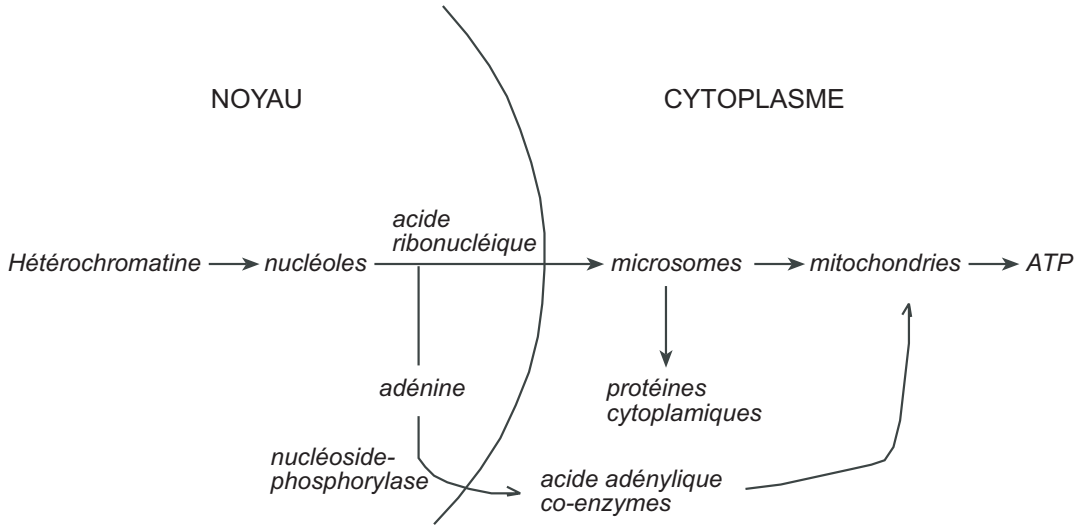

Figure 1. The scheme of protein synthesis redrawn from Brachet (1952, p. 115). This embryological diagram IS not a declaration of the "central dogma" that information is transferred only from nucleic acid to protein (Crick, 1970). Nonetheless, note the approximation to subsequently accepted details of the roles of the nucleic acids in the mechanisms of protein synthesis and that the feedback loops convey no information.

developed extremely strong support for a series of strikingly new claims. Before I show you how far he had gotten, note that this work was completed before the Hershey-Chase experiment, first published in 1952 (Hershey and Chase 1952), had demonstrated that the DNA in bacterial viruses probably served as their genetic material. It was also published before Watson and Crick announced their findings regarding the structure of DNA (Watson and Crick 1953). Here is an incomplete list, reflected in the sole diagram of a little book he published in 1952 (Brachet 1952, p. 115, see Figure 1). DNA occurs exclusively in the nucleus of cells; some RNA is found in the nucleus (and is probably formed under the influence of DNA); RNA is exported from the nucleus; most RNA is found in the cytoplasm; a major fraction of it is in ribosomes (themselves discovered during this period). Ribosomes also contain protein and, when proteins are formed, they seem to grow on or in conjunction with ribosomes. Finally, to be able to produce significant amounts of protein, cells must make or contain plentiful RNA.

The ramifications of this work and its connections with other work deserve detailed attention, and belong at the heart of a full-fledged case study, but for present purposes we can extract a straightforward point without further ado. Brachet made minimal use of theory until at least the middle of his career and always remained suspicious of over-dependence 
on theoretical assumptions. There was no theoretical principle, guideline, or expectation about the distribution of the nucleic acids that shaped Brachet's early work. Indeed, orthodox opinion when he began to work considered RNA to be a plant nucleic acid and DNA an animal nucleic acid-and did not identify nucleic acid as involved in any important way in protein synthesis. His early work thoroughly undermined the putative plant/animal distinction between the nucleic acids, and by 1938 he had identified RNA as a key participant in protein synthesis. The localization work that enabled him to do this was not based on methods of hypothesis testing, and not shaped by clear-cut theoretical assumptions until quite late in the game. Rather, it was based on an expanding toolkit of methods and instruments for tracing the spatio-temporal distribution of DNA, RNA, proteins, and other materials in cells and tissues during the development of a wide variety of organisms. And it was based on the opportunistic adaptation of new techniques, such as the use of radioactive tracers, to 'triangulate's on the locations, synthesis, and degradation of the substances he was investigating. Yet his findings, built on following the compounds, came to be of crucial importance for work on protein synthesis and for understanding the genetic controls that determine which proteins are made when. Brachet was drawn into these issues by his exploratory experiments, not on the basis of prior theoretical commitments. ${ }^{6}$

\section{Interim Conclusions}

I draw two morals from this and related case studies of exploratory experimentation. The first moral is that exploratory experimentation is widespread and comes in many modes - and that once one looks for it, it is easy to find examples in many disciplines. ${ }^{7}$ Yet exploratory experimentation is not a category found in standard top-down philosophy of science, as is easily confirmed by scanning even rather recent literature. The usual views,

5. The notion of triangulation is important and deserves wider exploitation. Some relevant sources are (Wimsatt 1981; Star 1986; Star and Griesemer 1988; Wimsatt 1991; Burian 1993a, 1993b; Wimsatt 1994; see also Culp 1994).

6. There is much more to say about the ways in which the entities at stake here-e.g., ribosomes and, for that matter, DNA and RNA—are constituted. They resemble, in certain respects at least, what Hans-Jörg Rheinberger calls 'epistemic objects', which are formed and reformed as the objects under investigation as characterized by the theoretical-plus-practical means of identifying them. For ribosomes see Rheinberger (Rheinberger $1995,1997 \mathrm{a}, 1997 \mathrm{~b})$ and for a more general treatment of 'epistemic things' see Rheinberger (Rheinberger 1997c).

7. See, for example, (Steinle MS 2001) for a case study showing that exploratory experimentation of the style described here is not restricted to the biological sciences or the nineteenth and twentieth centuries. 
based on philosophical models of hypothetico-deductive, inductive, and abductive inference, are limited to three major ways in which experiments are related to theories. Experiments can test hypotheses, they can generate and/or support hypotheses by induction, and they can determine which of the available explanations best fit the facts. Exploratory experimentation does not fit any of these standard models. Hence it is invisible, a fact that illustrates one way in which top-down philosophy produces systematic bias in interpreting scientific literature.

The second moral, to wit, that there are many different kinds of relationships between exploratory experimentation and high theory, is best supported by use of additional case studies. I mention three other cases that illustrate the spectrum toward greater involvement of theory. One concerns the efforts by Theodosius Dobzhansky, one of the founders of the synthetic theory of evolution, to utilize Sewall Wright's highly mathematical shifting balance theory of evolution to account for variation found in certain natural populations of Drosophila pseudoobscura in work done during the 1940s and 1950s. According to Wright's theory, there should be demes (genetically isolated local populations) that exhibit considerable random genetic variation in rapidly evolving populations. (The variation among demes provides the raw material for selection to change the composition of the whole population relatively quickly.) Dobzhansky's use of Wright's theory was undermined (but the theory was neither tested nor refuted) when he found that the seemingly random variation of some of the key populations he had examined was seasonally cyclic, and thus was a response to the environment guided by selection. ${ }^{8}$

Another case concerns the collaboration of François Jacob and Jacques Monod, amplified slightly below. These scientists began their joint work in the Pasteur Institute when they were both in the laboratory of André Lwoff, a microbial physiologist. Their collaboration led them to develop the concept of the operon, the basis for the first widely accepted model of gene regulation, applied in detail to the bacterium Escherichia coli. At one key phase, their experiments involved simply following the time course of events (including the synthesis of certain enzymes) when certain well-defined genetic material, donated by one strain of bacteria, was introduced into bacteria with a different, but also well-defined genetic consti-

8. For Dobzhansky, see (Dobzhansky 1981), including (Provine 1981), (Lewontin 1981), and the introductions to the individual articles, particularly IX, XII, and XX. For Wright, see (Provine 1986), the five papers co-authored with Dobzhansky included in (Dobzhansky 1981), and (Wright 1986), including Provine's introductions. For an interpretation of Dobzhansky's experimental style, and some ways in which significant portions of his experimental work do not fit an hypothesis testing models, see (Lewontin 1993). 
tution. This case is particularly interesting and complex because Jacob and Monod relied heavily on theory in designing their experiments and were in the business of testing hypotheses. Still, some of their most important results concerned unexpected findings that neither confirmed nor infirmed the high theory involved, but opened up new doors for studying what we now call regulation of gene expression. Unfortunately, it requires a large-scale account of this case to spell out the intricate interrelation between exploratory experimentation and theory involved.

A third example nicely illustrates that exploratory work remains at the heart of contemporary molecular genetics. Consider, for example, the 'gene knockout' experiments done on 'anonymous genes', identified in DNA sequence databases by the fact that they are downstream from a signal used in initiating transcription of genes (an 'open reading frame'). Many such experiments aim at detecting, if possible, what the products of those genes do-or, more exactly, what happens when disrupting the genes in question eliminates their products. ${ }^{9}$ These examples, and countless others, make it clear that exploratory experiments, rather like those that Brachet undertook, are ubiquitous in molecular biology-and in many other disciplines as well.

To work out the issues I have raised about the relation of exploratory experimentation to theory one needs to rely on case studies. The relationship between exploratory experiments and high theory depends on the domain under investigation, the state of our knowledge of that domain, and the power of the available research tools. It cannot be analyzed from first principles or from attention to the use of experiments central to philosophical accounts of scientific theories and explanations in theory-driven situations.

\section{Topic Two: Working Across Disciplines}

In a recent memoir, Of Flies, Mice, and Men, François Jacob writes, "In the early days of molecular biology, at mid-century, most research was the product of teams of two, of duos, of pairs" (Jacob 1998, p. 47). He mentions such prominent pairs as Beadle and Tatum, Luria and Delbrück, Perutz and Kendrew, Watson and Crick, Jacob and Monod, Meselson and Stahl. Many more such pairs could be added to his list. Strikingly, these pairs typically involve people who come from different disciplinary backgrounds. This is the phenomenon I discuss next.

9. For a philosophical paper that addresses an unusual example, but that reinforces the point and explores the difficulty of this exploratory work, see (Culp 1997) and my comments thereon (Burian 1997a). 
Case 2: Analyzing the Control of $\beta$-Galactosidase Synthesis in E. coli. My account of this case must be extremely telegraphic. However, the central point is easy to comprehend. It concerns the collaboration of Jacob and Monod in the work eventuating in the discovery of messenger RNA and the analysis of the operon, described in extenso in (Judson 1996, esp. chap. 7). ${ }^{10}$ One key set of experimental techniques employed Jacob's tools, acquired in his collaborative work with Elie Wollman on bacterial and bacteriophage genetics. These included manipulation of bacterial genomes so that they contained specific variants of specific genes and performing experiments in which genetically characterized donor bacteria from one culture simultaneously injected their DNA from a fixed starting point on the bacterial chromosome into genetically characterized recipient bacteria from a distinct culture. These techniques allowed one to map both bacterial and bacteriophage genes, to follow the time course of gene expression, and to study interactions between bacteria and bacteriophage.

Monod's experimental tools were based on fifteen years' intense biochemical analysis of the metabolism of lactose digestion in bacteria, including (like Jacob and Wollman) a special strain (K-12) of Escherichia coli. One of the primary techniques that Monod employed was biochemical kinetics. He provided an enormous stock of genetically distinct strains of $E$. coli that produced variant enzymes (often totally absent in related bacteria) required for the synthesis of $\beta$-galactosidase, an enzyme crucial for the digestion of lactose. A striking phenomenon kept his interest in this enzyme and its metabolism alive. Even when a gene required for synthesis of the enzyme was present in the bacteria, they did not make that enzyme except in extremely well defined conditions-in the typical case, only when the medium in which the bacteria lived contained no glucose, but did have plentiful lactose. Monod recognized that if he could get at the mechanism by which the bacteria controlled the production of B-galactosidase and metabolically related materials, he might have a way of understanding control of protein synthesis. He employed a rich armamentarium of inducers, inhibitors, and modifiers of $\beta$-galactosidase synthesis that could be used to test which steps were blocked and to ensure that specific genes were expressed or not expressed in cells of particular genetic constitutions.

The immediate point is that Monod did not have tools for manipulating DNA, for mapping genes, and for controlling crosses between bacte-

10. Jacob touches on this work in a partially popular, partially autobiographical vein in (Jacob 1998). For shorter recent treatments of this work, see (Morange 1998, chaps. 12 and 14) and (Burian and Gayon 1999). 
ria, while Jacob did not have a system subject to the fine-grained controls that Monod did. Neither could have done alone what they did together. In working together, they occasionally encountered key differences in their theoretical assumptions. A crucial example concerns Monod's strong commitment to the idea that control of the production of proteins could not involve direct interaction of other materials with DNA, which, he thought, could only be changed by mutation. ${ }^{11}$ In particular, protein synthesis took place in the cytoplasm and proteins were made on ribosomes, so no direct interaction of other materials with chromosomal DNA was required for protein synthesis as such. He held onto this commitment until sometime in 1957. In contrast, Jacob, who handled DNA in ways that Monod did not and who had studied the incorporation of bacteriophage genetic material into bacterial genomes, held that DNA interacted in many ways with other substances. DNA, for him, was not sacrosanct; in various circumstances it altered its behavior and its accessibility to interaction with other materials that altered its behavior. In brief, Monod thought of the genome as static up to mutation, while Jacob thought of it as dynamic.

Jacob and Monod's experiments on the time course of the production of $\beta$-galactosidase and related proteins when the relevant genes were introduced into novel cellular conditions eventually resolved this disagreement in favor of Jacob. The most famous of those experiments showed that what we now call gene expression began at full speed within seconds of the entry of DNA containing a functional $\beta$-galactosidase gene into a cytoplasm that did not have an inhibitor to block expression of the $\beta$-galactosidase gene. But the same set of experiments also showed that after about an hour, something new was present in the cytoplasm that blocked further expression of those genes (Pardee, Jacob, and Monod 1959).

Both Monod's fine-grained control of the variants of the system of galactosidase production and Jacob's system for injecting DNA from one strain of bacteria to another were needed to design the decisive experiments. It took both technologies, but without the battle to achieve experimental resolution of the discrepancies between their beliefs the technolo-

11. Until 1956 or 1957 , Monod thought that the control of production of different gene products occurred in the cytoplasm by mechanisms involving competition between the primary gene products for substrate and the template action of those products on protein precursors. This position employed the instructional models prevalent in immunology during this period and fit well with the views of many immunologists and biochemists about the mechanisms of protein production. Judson (Judson 1996) entitles his chapter on the Jacob-Monod collaboration with a characteristic quotation expressing Monod's attitude at the time: "The gene was something inaccessible." 
gies alone would not have been sufficient for them to achieve their vision of the operon. That vision, once without the battle to achieve experimental resolution of the discrepancies between their beliefs achieved, was beautiful and although it was fiercely debated, it quickly gained wide acceptance. The operon is a highly integrated system of control circuitry governing the behavior of several genes. At least one of these produces a soluble protein that travels through the cytoplasm and, perhaps in conjunction with other molecules, interacts with the DNA itself. In doing so, it regulates expression of all of the genes controlled by the operon, itself included, in effect by throwing a switch that blocks the transcription of mRNA. Such a protein is called a repressor.

The differences between the tools that Jacob and Monod brought to their joint work and the disparities between their underlying assumptions highlight the fact that each of them brought distinctive resources to bear in their intense and productive collaboration. Something of the sort is true for each of the pairs on Jacob's list. In these cases (and many more), the members of the pair drew on different disciplinary backgrounds or employed distinctive tools or technologies for gaining access to a common subject matter. Typically, they also discovered that their assumptions were divergent and that they had to resort to experiment to resolve which of their disagreeing intuitions (if either) was correct.

\section{More Interim Conclusions}

The central moral here is obvious, though controversial. The discrepancies in theoretical assumptions were resolved by experiments that drew on both Jacob's and Monod's sets of tools. The work was effective in part because those tools were used to resolve significant ambiguities in the interpretation of the experiments or disagreements about which processes and materials were involved in particular experimentally stable findings. In general, the pairs of collaborators reached agreement about the issues they studied because, in spite of the disparate theoretical assumptions and divergent beliefs about the behavior of key theoretical entities, they could satisfy themselves that they had gained access to the same underlying processes and entities.

Perhaps it is worth stressing that the agreement achieved concerned highly theoretical entities. In the case of Jacob and Monod, the operon and the repressor (the molecule that, in context, blocked mRNA synthesis)—a molecule that was utterly uncharacterized biochemically-surely count as theoretical entities! The collaborations on Jacob's list succeeded because the different tools brought to common projects could be used to triangulate on common objects and behaviors even when the collaborators held sharply differing positions about what those entities were and/or how they 
behaved. Epistemologically speaking, the lesson is that it is often possible for scientists with sharply different fundamental assumptions to isolate some properties of specific things or processes with a definite location in space and time, even though the things or processes in question count as theoretical entities. By thus localizing what they are talking about, in good cases, the collaborators can go on to pin down facets of the behavior of the objects they are investigating and test these decisively against the background of shared results. There is no guarantee of success in such investigations, but at least the outline of the pathway by means of which to probe the entities in question is clear.

Taking the matter one step further, I suggest that this sort of pinning down of entities, processes, and behaviors often involves - and may even require-'local' knowledge and highly specific devices for ensuring that the spatio-temporal localizations are properly fixed. In the case of Jacob and Monod, particular strains of E. coli, with known characteristics, particular biochemical inhibitors of $\beta$-galactosidase synthesis that intervened at known points in the synthetic chain, and the like provided the means for forcing resolution of their disagreements. And these tools, in turn, depended on some rather long traditions of work, including highly specific knowledge originating in the Pasteur Institute and in bacterial and bacteriophage genetics. The particularity of the tools is crucial. For example, only about 1 in 400 strains of $E$. coli permit the combination of controlled [i.e., inducible] synthesis of $\beta$-galactosidase and susceptibility to phage $\lambda$ both of which were required for the experiments carried out by Pardee, Jacob, and Monod. ${ }^{12}$ The strains of bacteria employed by Jacob and Monod derived from strains of E. coli K-12 supplied by Joshua Lederberg. The two investigators, each acting separately for his own purposes, had originally chosen the K-12 strains because they had one of the two capacities that turned out to be required for the key experiments of their collaboration. The 'local' knowledge of the specific genetic capacities of these key strains of bacteria was quite rare among bacterial geneticists at the time. Without it, the experimental resolution of the disagreement between Jacob and Monod about the interaction of other substances with DNA would not have occurred, at least not by the pathway that, in fact, produced the answer for them. ${ }^{13}$

12. Joshua Lederberg, personal communication. Ability to become lysogenic with phage $\lambda$ is present in roughly $1 / 20$ strains of $E$. coli; similarly for inducibility of $\beta$-galactosidase. These traits are independent, so the odds of a strain having both are roughly $1 / 400$.

13. For more on the importance of the choice of organism, see (Lederman and Burian 1993). For the more general issue of the importance of the choice of experimental tools and techniques, see (Clarke and Fujimura 1992). 
This dependence on highly particular knowledge shows the difficulty of providing a general characterization of what is required to 'triangulate' on a theoretical entity or behavior. One starts out with a strong disagreement. One is not certain whether the disagreement is due to differences in what is being talked about or to false assumptions about the behavior of specific entities, or to experimental artefacts, or to defective reagents, or ... - the list of possible sources of error can be continued indefinitely. In order to resolve the disagreement, one needs specific local knowledge about how the differing techniques involved interact with the materials or behaviors in question. Without that knowledge, the disagreement risks intractability because one cannot determine whether the parties have actually fixed on the same entity or behavior or cause of the phenomena in question. In forefront work, such as the exploratory work discussed today, it is extremely difficult to secure the desired triangulation until there are routinized means of access to the theoretical entities, processes, or behaviors under investigation. The specificity of what went into the resolution of the disagreement between Jacob and Monod within their collaboration suggests very strongly that it will not be possible to develop a satisfactory general account of what it takes to resolve such issues.

This point about local knowledge provides a grain of truth for Joe Pitt's claim that science is subject to Heracleitean flux. Typically (although, as it turns out, not in this instance) the highly specific knowledge of particular systems is relatively evanescent. The reasons for this can be highly contingent. Two examples: we cannot review the data from the Mercury series of rockets because there are no longer any computers available that have the sort of operating system needed to translate the data, which were electronically stored, into a form legible to humans. Because of scientific fashions, no one now knows the embryology of many of the marine organisms that were well studied in the late 19th century, though, typically, the data for this work are more readily available than the Mercury data.

But the sometimes-rapid turnover of local knowledge does not show that science is overcome by Heracleitean flux. Because most scientific knowledge is connected to publication and to broader problems that remain in the community for long periods of time, we are much better able to recover an account of the larger issues that drove much scientific work. Our hand is strengthened when we can reconstruct-whether physically or by simulation - the details of particular experiments and instruments. F. L. Holmes has explored what he calls the investigative pathways of individual scientists by means of which they develop technical approaches to particular problems and by means of which they come to move from one problem to another. I suggest that not only individuals follow investiga- 
tive pathways, but also groups of scientists who share a basic problem and even disciplines. It is, after all, possible to give a fairly sharp characterization of the differences between the investigative pathways by which geneticists and biochemists approached the problem of protein synthesis in the 1950s and early 1960s. The main body of disciplinary knowledge and of the multi-disciplinary knowledge applied to one of Pitt's 'problematics' does not turn over at anything like as great a rate as local knowledge. We are usually able to resolve questions on this scale even when we are not able to do so for some of the local knowledge that was deployed in attacking the problems that the scientists were investigating. This provides us multiple pathways for zeroing in — and for zooming in and out-as we explore the questions about relevance of context that Prof. Pitt despairs of ever solving.

\section{General Conclusions}

I shall offer two groups of conclusions. The first concerns the dilemma about the use of case studies put forward by Joe Pitt. The second concerns the implications of this paper for Kuhn's philosophy of science.

On the view underlying this paper, science has no essence. Its standards for the adequacy of argument, evidence, experimental technique, and theory change-and should change-with time, discipline, subject matter, and setting. As my case studies illustrate, the changes we explored are not Heracleitean, but orderly and strongly based on evidence. In context, there is a justified, if rough and ready, ordering of the relative epistemic security of claims. Fundamental assumptions can be overturned, but it takes a great deal more to do so than it does to overturn relatively incidental (supposed) matters of fact or intermediate-level experimental protocols, evidential evaluations, or putative laws. This is crucial for the very existence of the scientific problematics that play a key role in Prof. Pitt's argument. Although scientific investigation starts in the middle of things, it does not take place in an epistemic vacuum, a Heracleitean morass. Pervasive change does not imply radical relativism or loss of contact between science and an external world. Rather, as we have seen, in favorable cases hard-won experimental findings can be used to adjudicate scientific disputes. As Dudley Shapere emphasized (Shapere 1980) and our case studies illustrate, we learn how to learn as we learn.

These considerations allow us to escape the second horn of Pitt's dilemma. Given that science has no essence, we cannot expect to find universal methodological rules or philosophical principles that provide more than heuristic guidance. We must work in, and study, particular contexts and do our best to find valid, but limited generalizations. Such work is, 
inevitably, subject to the risk of hasty generalization and sample bias. If we seek objectivity, we must do our best to combat these risks, but no one can escape them. Pitt's dilemma should be taken seriously only by those who believe that there is a universal or objective scientific method or that philosophy can provide sufficient epistemological guidance to those who would seek truth in empirical matters. These beliefs, as we have seen, are poorly supported and highly suspect.

Case studies cannot and should not be expected to yield universal methodologies or epistemologies. Rather, they yield local or, better, regional standards - and fallible ones at that. As my discussion of the JacobMonod collaboration shows, to combat divergent assumptions it is crucial that the tools employed pin down the same entities or behaviors. One does not get much guidance about how to do this in general from the case study, though one does obtain some guidance for dealing with bacteria, DNA, RNA, and some proteins. But the heuristic principle that the case study yields is, I believe, valid: to resolve the choice between conflicting theoretical assumptions, try forging and using tools that are experimentally adequate to the task of identifying the entities and behaviors at stake with great specificity. To this extent, case studies like those explored today can make useful points in the methodology and philosophy of science.

The second set of general conclusions touches on a central Kuhnian issue. My case studies illustrate the solidity of some of the knowledge derived from exploratory experimentation and the continuities that can be forged by triangulation across disciplines and in the absence of deep theoretical commitments. Kuhnian philosophy of science cannot easily digest these important points, which conflict with the image of the centrality of paradigms in scientific disciplines and discontinuity across paradigms. For the sake of the argument suppose (what is surely false) that the conceptual structures at the heart of Kuhnian paradigms are so crystalline that they must be exchanged as wholes rather than by piecemeal processes. Given this, my case studies undermine the more extreme Kuhnian claims about the incommensurability of the interpretations of experiments by scientists working in different paradigms. (I think the extreme readings are fair to the original text of Kuhn's Structure of Scientific Revolutions, but my point is not about Kuhn exegesis, and so does not turn on how best to read Structure.) The case studies sketched above undermine incommensurability, taken strongly, because they reveal too many paradigm-independent means of achieving agreement about matters that are, in Hilary Putnam's useful term, transtheoretical (and hence transparadigmatic). The techniques for identifying a strain of bacteria force interpretative continuities on biologists, as do the techniques for determining whether or not a par- 
ticular enzyme or nucleic acid is present at a particular concentration at a particular place in a cell. These continuities are sufficient to enforce a partly common interpretation of key experimental results even when those results are used to resolve fundamental theoretical disagreements. In the Jacob-Monod case, this is part of what is meant by saying that studies of the time course of enzyme production produced facts that were independent of the conflicting theories of the experimenters. Properly understood, such facts are not wholly theory-independent and certainly not infallibly known, but we have learned how to establish them in ways that do not turn on the disputes they are used to resolve-even when Kuhn would consider those disputes to be disputes across paradigms. This is a major reason for denying Kuhn's occasionally extreme holism and Joe Pitt's new-found Heracleiteanism.

The turn to bottom up work in philosophy of science implies an important reduction in the ambitions of that discipline. We cannot expect case studies to yield or support universalizing methodologies or epistemologies. But the sacrifice of that sort of generality—or, rather, pseudo generality-allows both philosophers and historians to deal with concrete questions about how to improve empirical knowledge in the context of real knowledge situations-provided, of course, that they get the context right. This is more than philosophy can do by itself-it needs to engage with the science and relevant contexts involved. Furthermore, this result has epistemological bite. Properly amplified, it helps support the recent turn to practice in history and philosophy of science. It also reinforces the possibility of constructing a thoroughly fallibilist philosophy of science and sheds important light on the delicate-and contingent-interrelations between theory and experiment. For such questions, case studies provide the best resource available to the history and philosophy of science for understanding the practice of science.

\section{References}

Brachet, Jean. 1952. Le rôle des acides nucléiques dans la vie de la cellule et de l'embryon. Liége and Paris: Desoer and Masson.

- 1957. Biochemical Cytology. New York: Academic Press.

Burian, Richard M. 1985. "On Conceptual Change in Biology: The Case of the Gene." Pp. 21-42 in Evolution at a Crossroads. Edited by D. Depew and B. Weber. Cambridge, MA: MIT Press.

. 1993a. "Unification and coherence as methodological objectives in the biological sciences." Biology and Philosophy 8:301-318.

. 1993b. "Technique, task definition, and the transition from genetics to molecular genetics: Aspects of the work on protein synthesis 
in the laboratories of J. Monod and P. Zamecnik." Journal of the History of Biology 26: 387-407.

. 1994. "Jean Brachet's cytochemical embryology: Connections with the renovation of biology in France?" Pp. 205-220 in Les sciences biologiques et médicales en France 1920-1950. Edited by C. Debru, J. Gayon and J.-F. Picard. Paris: CNRS Éditions.

- 1996. "Underappreciated Pathways Toward Molecular Genetics as Illustrated by Jean Brachet's Chemical Embryology." Pp. 67-85 in The Philosophy and History of Molecular Biology: New Perspectives. Edited by S. Sarkar. Dordrecht: Kluwer.

. 1997a. "Comments on Complexity and Experimentation in Biology." Philosophy of Science 64 (Supplement):S279-S291.

. 1997b. "Exploratory Experimentation and the Role of Histochemical Techniques in the Work of Jean Brachet, 1938-1952." History and Philosophy of the Life Sciences 19:27-45.

_. 2003 [in press]. "'Historical Realism', 'Contextual Objectivity', and Changing Concepts of the Gene." Pp. in The Philosophy of Marjorie Grene. Edited by L. E. Hahn and R. E. Auxier. Carbondale, IL: Library of Living Philosophers.

Burian, Richard M., and Jean Gayon. 1999. "The French school of genetics: From physiological and population genetics to regulatory molecular genetics." Annual Review of Genetics 33:313-349.

Burian, Richard M., and Denis Thieffry, eds. 1997. "Research Programs of the Rouge Cloître." Vol. 19 (1), History and Philosophy of the Life Sciences.

Clarke, Adele E., and Joan H. Fujimura, eds. 1992. The Right Tools for the Job: At Work in 20th Century Life Sciences. Princeton: Princeton University Press.

Culp, Sylvia. 1994. "Defending Robustness: The Bacterial Mesosome as a Test Case." Pp. 46-57 in Proceedings of the Biennial Meetings of the Philosophy of Science Association, 1994

-. 1997. "Establishing genotype/phenotype relationships: Gene targeting as an experimental approach." Philosophy of Science 64 (4):S268-S278.

Dobzhansky, Theodosius. 1981. Dobzhansky's "Genetics of Natural Populations I-XLIII". Edited by R. C. Lewontin, J. A. Moore, W. B. Provine and B. Wallace. New York: Columbia University Press.

Donovan, Arthur, Larry Laudan, and Rachel Laudan, eds. [1988] 1992. Scrutinizing Science: Empirical Studies of Scientific Change. Dordrecht: Kluwer. Repr. ed. Baltimore: The Johns Hopkins University Press.

Franklin, Allan. 1990. Experiment, Right or Wrong. New York: Cambridge University Press. 
Hershey, Alfred D., and Martha Chase. 1952. "Independent Functions of Viral Protein and Nucleic Acid in Growth of Bacteriophage." Journal of General Physiology 36:39-56.

Howson, Colin, and Peter Urbach. 1989. Scientific Reasoning: The Bayesian Approach. La Salle, IL: Open Court.

Jacob, François. 1998. Of Flies, Mice, and Men. Translated by G. Weiss. Cambridge, MA: Harvard University Press.

Judson, Horace Freeland. 1996. The Eighth Day of Creation: Makers of the Revolution in Biology. Expanded Edition. Cold Spring Harbor: Cold Spring Harbor Laboratory Press.

Kuhn, Thomas S. 1962. The Structure of Scientific Revolutions. Chicago, Ill.: University of Chicago Press.

Lakatos, Imre. 1971. "History of sciences and its rational reconstructions." Pp. 1-39 in In Memory of Rudolf Carnap. Edited by R. Buck and R. S. Cohen. Dordrecht: Reidel.

- 1972. "Falsification and the Methodology of Scientific Research Programmes." Pp. 91-196 in Criticism and the Growth of Knowledge. Edited by I. Lakatos and A. Musgrave. Cambridge: Cambridge University Press.

Laudan, Larry. 1977. Progress and its Problems. Berkeley, CA: University of California Press.

Lederman, Muriel, and Richard M. Burian, eds. 1993. "The Right Organism for the Job." Special section, Journal of the History of Biology 26 (2):235-367.

Lewontin, Richard C. 1981. "Introduction: The scientific work of Th. Dobzhansky." In Dobzhansky's Genetics of Natural Populations. Edited by R. C. Lewontin, J. A. Moore, W. B. Provine and B. Wallace. New York: Columbia University Press.

- 1993. Th. Dobzhansky-A Theoretician Without Tools.

Morange, Michel. 1998. A History of Molecular Biology. Translated by M. Cobb. Cambridge, MA: Harvard University Press.

Pardee, Arthur B., François Jacob, and Jacques L. Monod. 1959. "The Genetic Control and Cytoplasmic Expression of 'Inducibility' in the Synthesis of ß-Galactosidase by Escherichia coli." Journal of Molecular Biology 1:165-176.

Provine, William B. 1981. "Origins of the Genetics of Natural Populations Series." Pp. 1-83 in Dobzhansky's Genetics of Natural Populations, I-XLIII. Edited by R. C. Lewontin, J. A. Moore, W. B. Provine and B. Wallace. New York: Columbia University Press.

. 1986. Sewall Wright and Evolutionary Biology. Chicago: University of Chicago Press. 
Rheinberger, Hans-Jörg. 1995. "From microsomes to ribosomes: 'Strategies' of 'representation'." Journal of the History of Biology 28 (1):49-89. . 1997a. "Cytoplasmic Particles in Brussels (Jean Brachet, Hubert Chantrenne, Raymond Jeener) and at the Rockefeller (Albert Claude), 1935-1955." History and Philosophy of the Life Sciences 19:47-67.

. 1997b. "Experimental complexity in biology: Some epistemological and historical remarks." Philosophy of Science 64 (Supplement):S279-S291.

-. 1997c. Towards a History of Epistemic Things: Synthesizing Proteins in the Test Tube. Edited by T. Lenoir and H. U. Gumbrecht, Writing Science. Stanford, CA: Stanford University Press.

Sapp, Jan. 1986. Beyond the Gene: Cytoplasmic Inheritance and the Struggle for Authority in Genetics. New York: Oxford University Press.

- 1997. "Interview of Jean Brachet, Arco Felice, Italy, December 10, 1980." History and Philosophy of the Life Sciences 19 (1):69-87.

Shapere, Dudley. 1980. "The character of scientific change." Pp. 61-101 in Scientific Discovery, Logic and Rationality. Edited by T. Nickles. Dordrecht: D. Reidel.

Star, Susan Leigh. 1986. "Triangulating Clinical and Basic Research: British Localizationists, 1870-1906." History of Science 24:29-48.

Star, Susan Leigh, and James R. Griesemer. 1988. "Institutional Ecology, 'Translations,' and Boundary Objects: Amateurs and Professionals in Berkeley's Museum of Vertebrate Zoology, 1907-1939." Social Studies of Science 19:387-420.

Steinle, Friedrich. MS 2001. "Experiments in history and philosophy of science." Original edition, Paper delivered at the History of Science Society, November 2001.

Thieffry, Denis, and Richard Burian. 1996. "Jean Brachet's scheme for protein synthesis." Trends in the Biochemical Sciences 26 (3):114-117.

Watson, James D., and Francis H. C. Crick. 1953. "Molecular Structure of Nucleic Acids." Nature 171:737-738.

Wimsatt, W. C. 1981. "Robustness, Reliability, and Overdetermination." Pp. 124-162 in Scientific Inquiry and the Social Sciences. Edited by Brewer, M. B. and D. T. Casmpbell. San Francisco: Jossey-Bass.

- 1991. "Taming the Dimensions-Visualizations in Science." Pp. 111-135 in PSA 1990. Edited by Forbes, M., L. Wessels and A. Fine. East Lansing: The Philosophy of Science Association

— 1994. "The Ontology of Complex Systems: Levels of Organization, Perspectives, and Causal Thickets." Canadian Journal of Philosophy Supplementary Volume \#20: 207-274

Wright, Sewall. 1986. Evolution: Selected Papers. Edited by W. B. Provine. Chicago: University of Chicago Press. 